\title{
Thermodynamic Study on Hydrotropic Aggregation Behavior of Theophylline
}

\author{
Chinnakannu Jayakumar, ${ }^{1, *}$, Reddy Prasad D.M ${ }^{2}$ \\ ${ }^{1}$ Department of Applied Science and Technology, A. C. College of Technology, Anna University, Chennai, Tamil Nadu, INDIA. \\ ${ }^{2}$ Petroleum and Chemical Engineering Programme Area, Faculty of Engineering, Universiti Teknologi Brunei, BRUNEI.
}

\begin{abstract}
Objectives: A systematic study is required to enhance the solubility of insoluble fluid drugs that are only sparingly soluble. Hydrotropy may be a distinctive development to reinforce the liquid solubility of poorly water-soluble drugs. Materials and Methods: The term hydrotropic has been wont to designate the rise in the solubility of assorted substances in water because of the presence of enormous amounts of additives. Sodium salicylate, sodium benzoate, and resorcinol are utilized to reinforce the liquid solubility of many poorly soluble drugs. Varied organic solvents like methyl alcohol, chloroform, alcohol, dimethylformamide, and benzene are utilized for the solubilization of poorly soluble drugs. Theophylline drug was accessories to numerous hydrotrope concentrations $(0-3 \mathrm{~mol} / \mathrm{L})$ and also the non-inheritable sample for a solubility determination was analyzed in an exploitation UV spectrophotometer. Results: The solubility of theophylline has been specifically found to improve with an increase in hydrotrope concentration and also with a device temperature likely to be close to that of other organic compounds and drugs. Conclusion: To initiate substantial solubilization of the theophylline compound, a minimum hydrotrope concentration ( $\mathrm{MHC}$ ) in the aqueous phase was needed. As a consequence of the improvement in the solubilization of theophylline, the coefficient of mass transfer was also observed to expand with an increase in the hydrotropic concentration at $303 \mathrm{~K}$. To have a substantial enhancement within the mass transfer coefficient, a threshold value equivalent to $\mathrm{MHC}$ is to be maintained. For all sets of experiments, the maximal enhancement factor, which is the value ratio between the presence and absence of a hydrotrope, has been calculated. Thermodynamic parameters such as Gibb's free energy, enthalpy, and entropy of theophylline were calculated to determine the hydrotropic aggregation activity of theophylline. With an increase in system temperature, Gibb's free energy declines. It was found that the aggregation of hydrotropes was exothermic and preferred by a positive entropy value.
\end{abstract}

Key words: Hydrotropy, Theophylline, Solubility, Enhancement Factor, Aggregation Properties.

\section{INTRODUCTION}

Neuberg discovered in 1916 that the solution of some salts can increase the solubility in water of certain otherwise water-insoluble compounds. Hydrotrope or hydrotropism is a development that improves the liquid solubility caused by the third component or additive of drugs that are normally insoluble or poorly soluble in water. Booth and Everson were the primary ones to discover that with the hydrotrope concentration within the hydrotropic resolution, the increase in solubility does not happen linearly. This is a very important truth, although it is very important to interpret the hydrotrope mechanism..$^{1-3}$ Most of the recent advances in the hydrotropic area have been examined by Balasubramanian and Friberg, apart from separations, stressing the similarity between the aggregation actions of hydrotropes and surfactants. ${ }^{4,5}$ As a possible and industrially desirable technique, hydrotrope will be con-
Submission Date: 01-02-2021; Revision Date: 07-04-2021; Accepted Date: 09-08-2021

DOI: 10.5530/ijper.55.3s.176 Correspondence:

Dr. Chinnakannu Jayakumar,

Department of Applied Science and Technology, A. C. College of Technology, Anna University, Chennai- 600025, Tamil Nadu, INDIA.

Phone: +91 8838429067, Email-c_jayakumar73@ yahoo.com/dmr.prasad@utb. edu.bn

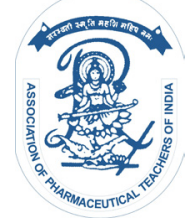

www.ijper.org 
sidered. The established increase in solubility is greater than that is caused by various well-known solubilization techniques. Surface-active, non-toxic, and strong properties are the features of hydrotropes. Quick regeneration of the dissolved material and the use of hydrotropes is the benefit of the hydrotropic technique. ${ }^{6-9}$ The MHC (Minimum Hydrotropic Concentration), which is outlined since the concentrations tend to combine at certain hydrotropic molecules, is said to be the most distinctive of the hydrotropes. The flexibility of hydrotropes to increase the solubility of organics in water is usually highest when the hydrotrope concentration is sufficient to cause the production of related structures. Hydrotropes have many functional uses, such as separation methods, the production of pharmaceutical formulations, the interaction of detergent solutions with cloud points, improvements in reaction rate, etc. However, the pharmaceutical industry is unable to supply itself with particle engineering technology capable of improving the degradation of poorly soluble compounds. Hydrotropes have many functional applications, such as separation methods, the production of pharmaceutical formulations, the interaction of detergent solutions with cloud points, changes in reaction rate, etc. However, there remains an unmet got to equip the pharmaceutical industry with particle engineering technologies capable of enhancing the dissolution of poorly soluble compounds. Hydrotropic solubilization technology is one such innovative technology. ${ }^{10-12}$ Theophylline also referred to as 1, 3-dimethylxanthine $\left(\mathrm{C}_{7} \mathrm{H}_{8} \mathrm{~N}_{4} \mathrm{O}_{2}\right)$ (Figure 1), is a phosphodiesterase-inhibiting drug used under several brand names in the treatment of respiratory disorders such as chronic obstructive pulmonary disease (COPD) and asthma. ${ }^{13-15}$ Theophylline is used to prevent and cure asthma, chronic bronchitis, emphysema and other lung disorders that cause wheezing, shortness of breath and chest tightness. It relaxes and opens air passages in the lungs and creates more space for air to move through. Theophylline is available under numerous brand names: Theo 24, Theochron, Elixophyllin, Uniphyland Aminophyllin. ${ }^{16-18}$

\section{MATERIALS AND METHODS}

All chemicals used were of analytical grade and bought from Sisco Research Laboratories Pvt. Ltd, Mumbai, India. Theophylline tablets were purchased from the local market.

\section{Spectrophotometric method analysis of theophylline bulk sample}

The solubility study of theophylline drug using different hydrotropes was carried out by applying an excess of

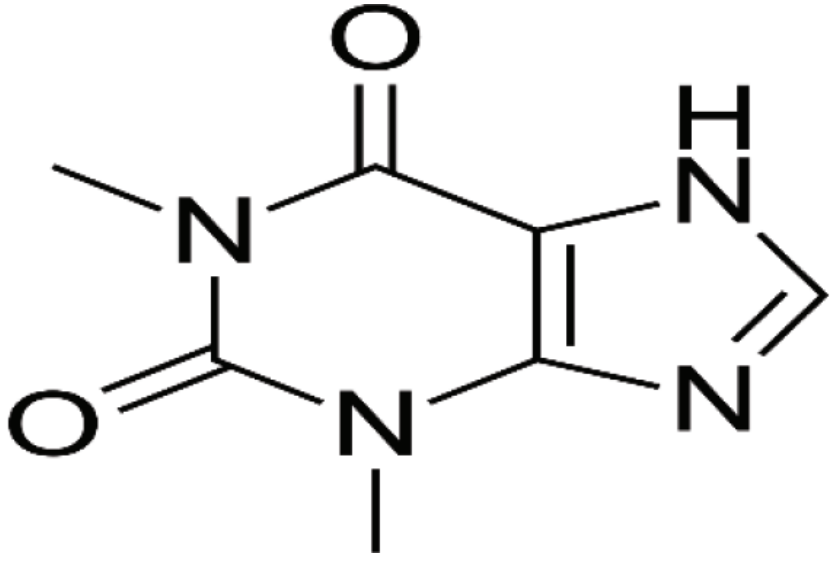

Figure 1: Structure of Theophylline.

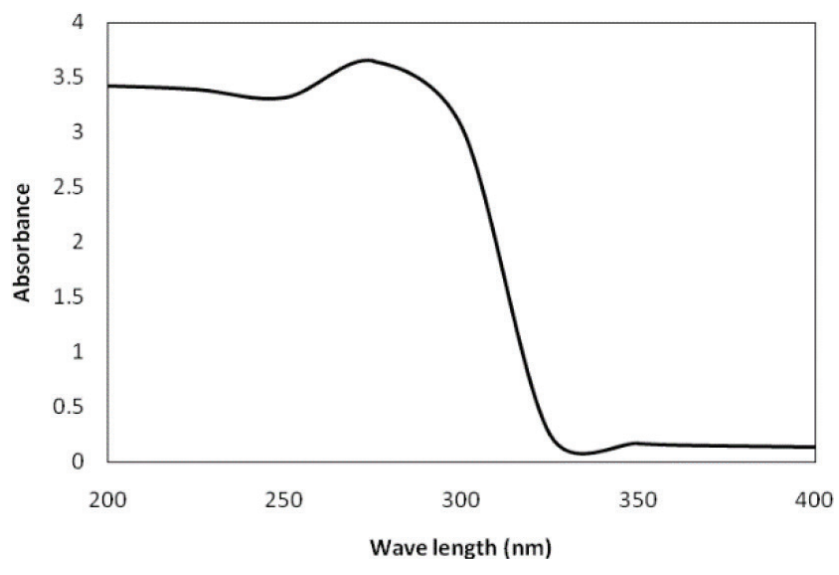

Figure 2: $\lambda_{\max }$ Graph for Theophylline.

theophylline to a range of hydrotropic solutions ( 0.1 to $3.0 \mathrm{~mol} / \mathrm{L})$ in $50 \mathrm{ml}$ of the screwed glass vial. The vial on a mechanical shaker was shaking for $12 \mathrm{hrs}$. In important to maintain equilibrium, the setup was kept for $24 \mathrm{hrs}$. The solution was centrifuged for 10 min after equilibration was obtained, and the supernatant was distilled by Whatman filter paper no.1 and then diluted correctly. A UV-spectrophotometer (Shimadzu Model: 1800) at $274 \mathrm{~nm}$ (Figure 2) has been used to analyze the concentration of theophylline in the supernatant. ${ }^{19-22}$

\section{Enhancement factor}

The enhancement factor is defined as the ratio of solubility of the system in presence of hydrotrope to the absence of hydrotrope. i.e., the solubility of the system at a maximum concentration of the hydrotrope to the solubility of the system in water. ${ }^{23-25}$ 

Enhancement factor $=\frac{\text { Solubility value in the presence of hydrotrope }}{\text { Solubility value in the absence of hydrotrope }}$

(1)

\section{RESULTS AND DISCUSSION}

Experimental results representing the effects of hydrotropes on the solubility of theophylline, i.e., sodium salicylate, sodium benzoate, and resorcinol, are presented in Tables 1-3 and are presented in Figures 3. One of the hydrotropes used in this study is sodium salicylate. The solubility of theophylline in the water at $303 \mathrm{~K}$ is $4.50 \times 10^{-2} \mathrm{~mol} / \mathrm{L}$ in the absence of any hydrotrope. It was observed that even after the addition of $0.40 \mathrm{~mol} / \mathrm{L}$ of sodium salicylate in the aqueous phase, the solubility of theophylline in water showed no appreciable increase. However, the solubility of theophylline in water was investigated to improve considerably with the resulting increase in the concentration of sodium salicylate above $0.40 \mathrm{~mol} / \mathrm{L}$. This aqueous phase concentration of sodium salicylate, i.e. $0.40 \mathrm{~mol} / \mathrm{L}$, is referred to as the Minimum Hydrotrope Concentration (MHC), which is the minimum required aqueous phase concentration of sodium salicylate (hydrotrope), above which the solubility of theophylline in water increases considerably. For other hydrotropes, a similar process has also been observed in the $\mathrm{MHC}$ requirement in the aqueous phase. Therefore, it is apparent that hydrotropic solubilization is shown only above MHC, which could be a hydrotropic feature for each solution. In the sense of the recovery of hydrotrope solutions, this $\mathrm{MHC}$ value

\begin{tabular}{|c|c|c|}
\hline \multicolumn{3}{|c|}{$\begin{array}{c}\text { Table 1:Effect of sodium salicylate concentration (c) } \\
\text { on the solubility (s) of theophylline in water. }\end{array}$} \\
\hline $\mathbf{C}, \mathbf{m o l} / \mathbf{L}$ & $\boldsymbol{\lambda}=\mathbf{2 7 4} \mathbf{~ n m}$ & $\mathbf{1 0}^{2} \mathbf{S}, \mathbf{~ m o l} / \mathbf{L}$ \\
\hline 0.10 & 0.850 & 85.892 \\
\hline 0.20 & 0.873 & 90.528 \\
\hline $0.40(\mathrm{MHC})$ & 0.886 & 93.147 \\
\hline 0.60 & 0.895 & 94.961 \\
\hline 0.80 & 0.906 & 97.178 \\
\hline 1.00 & 0.928 & 101.612 \\
\hline 1.20 & 0.935 & 103.022 \\
\hline 1.40 & 0.945 & 105.038 \\
\hline 1.60 & 0.956 & 107.255 \\
\hline 1.80 & 0.968 & 109.673 \\
\hline 2.00 & 0.975 & 111.084 \\
\hline 2.20 & 0.978 & 111.689 \\
\hline 2.40 & 0.983 & 112.696 \\
\hline $2.60\left(\mathrm{C}_{\max }\right)$ & 0.989 & 113.905 \\
\hline 2.80 & 0.992 & 114.510 \\
\hline 3.00 & 0.997 & 115.517 \\
\hline & & \\
\hline
\end{tabular}

Table 2: Effect of sodium benzoate concentration (c) on the solubility (s) of theophylline in water.

\begin{tabular}{|c|c|c|}
\hline $\mathbf{C}, \mathbf{~ m o l} / \mathbf{L}$ & $\boldsymbol{\lambda}=\mathbf{2 7 4} \mathbf{~ n m}$ & $\mathbf{1 0}^{2} \mathbf{S}, \mathbf{~} \mathbf{O} / \mathbf{L}$ \\
\hline 0.10 & 0.655 & 46.594 \\
\hline 0.20 & 0.663 & 48.206 \\
\hline $0.40(\mathrm{MHC})$ & 0.668 & 49.214 \\
\hline 0.60 & 0.675 & 52.625 \\
\hline 0.80 & 0.682 & 52.036 \\
\hline 1.00 & 0.685 & 52.640 \\
\hline 1.20 & 0.693 & 54.252 \\
\hline 1.40 & 0.697 & 55.058 \\
\hline 1.60 & 0.705 & 56.671 \\
\hline 1.80 & 0.712 & 58.081 \\
\hline 2.00 & 0.724 & 60.499 \\
\hline 2.20 & 0.735 & 62.716 \\
\hline 2.40 & 0.739 & 63.523 \\
\hline $2.60\left(\mathrm{C}_{\max }\right)$ & 0.745 & 64.732 \\
\hline 2.80 & 0.749 & 65.538 \\
\hline 3.00 & 0.753 & 66.344 \\
\hline
\end{tabular}

\section{Table 3: Effect of resorcinol concentration (c) on the} solubility (s) of theophylline in water.

\begin{tabular}{|c|c|c|}
\hline C, mol/L & $\lambda=274 \mathrm{~nm}$ & $10^{2} \mathrm{~S}, \mathrm{~mol} / \mathrm{L}$ \\
\hline 0.10 & 0.450 & 05.280 \\
\hline 0.20 & 0.465 & 08.303 \\
\hline $0.40(\mathrm{MHC})$ & 0.470 & 09.310 \\
\hline 0.60 & 0.474 & 10.117 \\
\hline 0.80 & 0.478 & 10.923 \\
\hline 1.00 & 0.484 & 12.132 \\
\hline 1.20 & 0.495 & 14.349 \\
\hline 1.40 & 0.510 & 17.372 \\
\hline 1.60 & 0.524 & 20.193 \\
\hline 1.80 & 0.535 & 22.410 \\
\hline 2.00 & 0.542 & 23.821 \\
\hline 2.20 & 0.550 & 25.433 \\
\hline 2.40 & 0.557 & 26.844 \\
\hline $2.60\left(C_{\max }\right)$ & 0.562 & 27.852 \\
\hline 2.80 & 0.568 & 29.061 \\
\hline 3.00 & 0.574 & 30.270 \\
\hline
\end{tabular}

assumes greater importance. Since hydrotrope seems to work only at large hydrotropic concentrations in water, the dissolved theophylline is released by most hydrotropic solutions when diluted with water below MHC. In general, knowledge of the $\mathrm{MHC}$ values is required at the industrial level as it ensures ready recovery of the hydrotrope for reuse. 


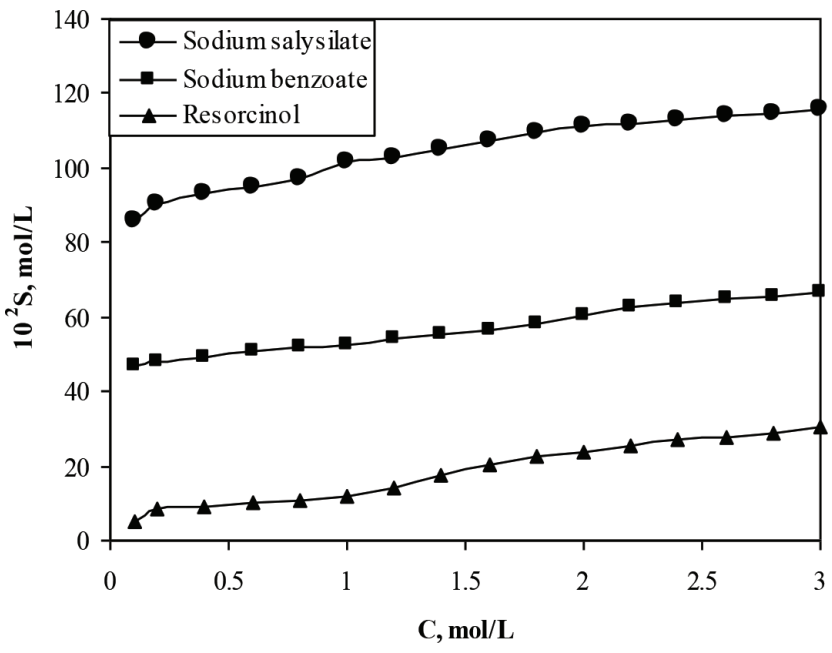

Figure 3: Effect of different hydrotrope concentrations (C) on the solubility (S) of theophylline in water.

\begin{tabular}{|c|c|c|}
\hline \multicolumn{2}{|c|}{ Table 4: MHC and $\mathbf{C}_{\max }$ values of hydrotropes. } \\
\hline Hydrotropes & $\begin{array}{c}\text { MHC } \\
\text { (mol / L) }\end{array}$ & $\begin{array}{c}\mathbf{C}_{\max } \\
\text { (mol/ } \mathbf{~})\end{array}$ \\
\hline Sodiumsalicylate & 0.40 & 2.40 \\
\hline Sodium benzoate & 0.40 & 2.40 \\
\hline Resorcinol & 0.40 & 2.60 \\
\hline
\end{tabular}

The solubilization effect varies with the number of different hydrotropes (Tables 1-3). A significant increasing trend in the solubility of theophylline above the MHC of sodium salicylate was found in this situation (Table 1). In the aqueous phase, this increasing phenomenon is maintained only up to a certain sodium salicylate concentration, above which there is no significant rise in the solution. This sodium salicylate (hydrotrope) concentration is referred to as the highest hydrotrope concentration in the aqueous phase $\left(\mathrm{C}_{\max }\right)$. The theophylline-related $\mathrm{C}_{\max }$ values of sodium salicylate, sodium benzoate, and resorcinol are 2.40, 2.60 and $2.60 \mathrm{~mol} / \mathrm{L}$, respectively (Table 4). From the study of the experimental results, it is found that further rises in the concentration of hydrotrope above $\mathrm{C}_{\text {max }}$ do not result in any substantial increase in the solubility of theophylline in the aqueous phase, including up to $2,40 \mathrm{~mol} / \mathrm{L}$ of sodium salicylate. In this analysis, the knowledge of the MHC and $\mathrm{C}_{\max }$ values of each hydrotrope for a specific solute assumes greater importance as it indicates the beginning and saturation of the hydrotropes' solubilization effect. However, the hydrotrope effect was observed to be significant in most situations at concentrations close to the $\mathrm{C}_{\max }$ value of the hydrotrope. The hydrotropeto-theophylline $\mathrm{MHC}$ and $\mathrm{C}_{\max }$ values can be useful for

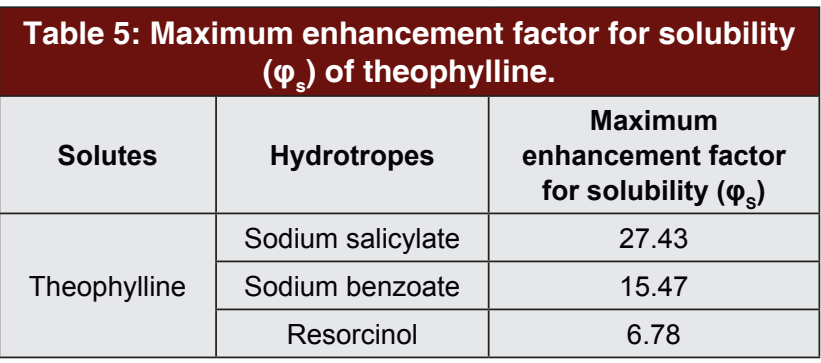

determining the recovery of the dissolved theophylline to the sum of the determined hydrotrope solution volume at any concentration between $\mathrm{MHC}$ and $\mathrm{C}_{\max }$ by easy dilution with distilled water. This is the hydrotropic solubilization technique's unique benefit. From the experimental data shown in Figure 3, it has been observed that similar to other hydrotropes, the concentration of sodium salicylate needed in the aqueous phase to achieve the desired solubility of theophylline has decreased. Three different regions were observed in the concentration range of sodium salicylates between 0.10 and $2.40 \mathrm{~mol} / \mathrm{L}$. It was inactive below $0.40 \mathrm{~mol} / \mathrm{L} \mathrm{MHC}$, beyond which there was a significant improvement in the solubility of theophylline up to $2.40 \mathrm{~mol} / \mathrm{L} \mathrm{C}_{\max }$, above which there was no more solubilizing impact of the hydrotrope. Sodium salicylate was also found to be an important hydrotrope in the theophylline concentration range between 0.40 and $2.40 \mathrm{~mol} / \mathrm{L}$ (Figure 3). The solubilization effect of sodium salicylate was also found not to be a linear function of the sodium salicylate solution concentration. For the theophylline with water process at $303 \mathrm{~K}$, the maximum enhancement factor value 27.43 is observed in Table 5. The solubilization effect of other hydrotropes, namely sodium benzoate and resorcinol has shown a different phenomenon. ${ }^{26-28}$

\section{Aggregation Properties of hydrotropes}

Variations in enthalpy, entropy, and free energy correlated with the aggregation of hydrotropes, such as sodium salicylate, sodium benzoate, and resorcinol, at a system temperature of $303 \mathrm{~K}$ at a wide range of hydrotropic concentrations $(0.1$ to $3.0 \mathrm{~mol} / \mathrm{L})$ were calculated and presented in Table 6 . As determined in the solution, the measurements are based on MHC.

$$
\Delta \mathrm{G}^{0}=\mathrm{RT} \ln \left(\mathrm{X}_{\mathrm{MHC}}\right)
$$

Where, $\mathrm{X}_{\mathrm{MHC}}=$ Solubility of theophylline at MHC, mol / L The free energy decreases with an increase in temperature as reported in Table 6.

The standard enthalpy $\left(\Delta \mathrm{H}^{0}\right)$ of aggregation can be found by the Van't Hoff equation, 


\begin{tabular}{|c|c|c|c|c|c|c|}
\hline Solutes & Hydrotropes & Temp, $\mathrm{K}$ & $\begin{array}{c}\text { MHC, } \\
\text { (by solubility) } \\
10^{3} \mathrm{~S},(\mathrm{~mol} / \mathrm{L})\end{array}$ & $\begin{array}{c}\Delta \mathrm{G}^{\circ}, \\
(\mathrm{kJ} / \mathrm{mol})\end{array}$ & $\begin{array}{c}\Delta \mathbf{H}^{\circ}, \\
(\mathrm{kJ} / \mathrm{mol})\end{array}$ & $\begin{array}{c}\Delta \mathbf{S}^{\circ} \\
(\mathrm{kJ} / \mathrm{mol})\end{array}$ \\
\hline \multirow[t]{3}{*}{ Theophylline } & Sodium salicylate & 303 & 9.314 & -5.979 & -1.755 & 0.0130 \\
\hline & Sodium benzoate & 303 & 4.921 & -7.586 & -3.282 & 0.0142 \\
\hline & Resorcinol & 303 & 0.931 & -11.781 & -1.450 & 0.0341 \\
\hline
\end{tabular}

$$
\Delta \mathrm{H}^{0}=-\mathrm{RT}^{2}\left(\partial \ln \mathrm{X}_{\mathrm{MHC}} / \partial \mathrm{T}\right)
$$

The slope in the plot of $\ln \left(\mathrm{X}_{\mathrm{MHC}}\right)$ versus $\mathrm{T}$ at each temperature was taken as $\left(\partial \ln \mathrm{X}_{\mathrm{MHC}} / \partial \mathrm{T}\right)$. A linear plot was observed for both the hydrotropes. The values of enthalpy are negative which indicates the aggregation behaviour of exothermic nature. The standard entropy $\left(\Delta S^{0}\right)$ of aggregation was calculated from

$$
\Delta S^{0}=\left[\left(\Delta H^{0}-\Delta G^{0}\right) / T\right]
$$

The change in entropy in all cases is positive, confirming that entropic aggregation of hydrotropes is preferred. However, as in Table 6, the values decrease as the temperature rises. This may be because, due to improve molecular motion at elevated temperatures, self-aggregation becomes weak at a higher temperature. ${ }^{29-30}$

\section{CONCLUSION}

Theophylline solubility, which is essentially insoluble in water, has been increased to a maximum value of $115.517 \times 10^{2} \mathrm{~mol} / \mathrm{L}$ in the presence of sodium salicylate as a hydrotrope at a system temperature of $303 \mathrm{~K}$. In the presence of sodium salicylate as hydrotrope at 303 $\mathrm{K}$, the maximum enhancement factor for the solubility $\left(\varphi_{S}\right)$ of theophylline was also increased to a maximum value of 27.43. Sodium salicylate is therefore found to be the most effective hydrotrope for enhancing the solubility of the poorly soluble theophylline compound. In the case of a hydrotrope, solubility is considered useful for studying thermodynamic stability. From the data obtained from this analysis, it is found that, compared to micellar surfactants, hydrotrope concentration gives self-aggregation at a minimum concentration. An unparalleled increase in the solubilizing effect of hydrotropes is due to the creation, at a specific concentration, of structured aggregates of hydrotropic molecules. With an increase in system temperature due to increase solubilization of solutes, the normal Gibbs free energy $\left(\Delta \mathrm{G}^{\circ}\right)$, Standard enthalpy $\left(\Delta \mathrm{H}^{0}\right)$, and Standard entropy $\left(\Delta S^{0}\right)$ of the solubilization of solutes decrease with an increase in system temperature.

\section{ACKNOWLEDGEMENT}

We would like to thank the Department of Applied Science and Technology, A.C. College of Technology, Anna University, for providing the facilities, and resources to carry out the research work.

\section{CONFLICT OF INTEREST}

The authors declare no conflicts of interest.

\section{ABBREVIATIONS}

MHC: Minimum Hydrotrope Concentration; Cmax: Maximum Hydrotrope Concentration; $\mathbf{X}_{\mathrm{MHC}}$ : Solubility of theophylline at MHC; $\varphi_{\mathrm{s}}$ : Maximum Enhancement Factor for solubility; $\Delta \mathbf{G}^{\circ}:$ Standard Gibbs free energy; $\Delta \mathbf{H}^{\circ}:$ Standard Enthalpy; $\Delta \mathbf{S}^{\circ}$ :Entropy.

\section{REFERENCES}

1. Saleh AM, El-Khordagui LK. Hydrotropic agents: a new definition. International Journal of Pharmaceutics. 1985;24(2-3):231-8. doi: 10.1016/03785173(85)90023-7.

2. Phatak PV, Gaikar VG. Solubility of o- and p-chlorobenzoic acids in hydrotrope solutions. J Chem Eng Data. 1993;38(2):217-20. doi: 10.1021/je00010a007.

3. Jain AK. Solubilization of indomethacin using hydrotropes for aqueous injection. Eur J Pharm Biopharm. 2008;68(3):701-14. doi: 10.1016/j. ejpb.2007.06.013, PMID 17716879.

4. Wagle VB, Kothari PS, Gaikar VG. Effect of temperature on aggregation behavior of aqueous solutions of sodium cumene sulfonate. J Mol Liq. 2007;133(1-3):68-76. doi: 10.1016/j.molliq.2006.07.006.

5. Srinivas $V$, Balasubramanian $D$. When does the switch from hydrotropy to micellar behavior occur? Langmuir. 1998;14(23):6658-61. doi: 10.1021/ la980598c.

6. Friberg SE, Brancewicz C, Morrison DS. O/W Microemulsions and Hydrotropes: The Coupling Action of a Hydrotrope. Langmuir. 1994;10(9):2945-9. doi: 10.1021/la00021a016.

7. Jayakumar C, Antony BM, Rajasekhar RG. Quantitative analysis of famotidine bulk sample using sodium salicylate hydrotrope. Int J Inst Pharm Life Sci. 2012;2:2249.

8. Saleh AM, Ebian AR, Etman MA. Solubilization of water by hydrotropic salts. J Pharm Sci. 1986;75(7):644-7. doi: 10.1002/jps.2600750705, PMID 3761164.

9. Reddy Prasad DM, Senthilkumar R, Lakshmanarao G, Krishnan S, Naveen Prasad BS. A critical review on thermal energy storage materials and systems for solar applications. AIMS Energy. 2019;7(4):507-26.doi: 10.3934/ energy.2019.4.507.

10. Balasubramanian D, Srinivas V, Gaikar VG, Sharma MM. Aggregation behavior of hydrotropic compounds in aqueous solution. J Phys Chem. 1989;93(9):3865-70. doi: 10.1021/j100346a098. 
11. Senthilkumar R, Reddy Prasad DM, Govindarajan L, Saravanakumar K, Naveen Prasad BS. Improved sorption of reactive black 5 by date seedderived biochar: isotherm, kinetic, and thermodynamic studies. Sep Sci Technol. 2019;54(15):2351-60. doi: 10.1080/01496395.2018.1547318.

12. Kim JY, Kim S, Papp M, Park K, Pinal R. Hydrotropic solubilization of poorly water-soluble drugs. J Pharm Sci. 2010;99(9):3953-65. doi: 10.1002/ jps.22241. PMID 20607808.

13. Kan T, Shimada Y, Sato F, Ito T, Kondo K, Watanabe G, Maeda M, Yamasaki S, Meltzer SJ, Imamura M. Prediction of lymph node metastasis with use of artificial neural networks based on gene expression profiles in esophageal squamous cell carcinoma. Ann Surg Oncol. 2004;11(12):1070-8. doi: 10.1245/ASO.2004.03.007, PMID 15545505.

14. Jayakumar C, Deepak KK, Nesakumar D. Quantitative analysis of theophylline bulk sample using sodium salicylate hydrotrope. Indian J Pharm Sci. 2010;2:0975.

15. Maheshwari RK, Bhatt P. Simultaneous spectrophotometric estimation of norfloxacin and tinidazole in two component tablet formulations. Asian J Chem. 2006;18:1481-6.

16. Jayakumar C, Sampath KV, Raja C. Thermodynamic study on hydrotropic aggregation behavior of mebendazole. Int J Res. 2020;7:540.

17. Jayakumar C, Mansa DV, Reddy PDM, Sridar R. A study on the extraction of bioactive compounds from Capparis zeylanica. AIP Conf Proc. 2020;2225(1):70002.

18. Coffman RE, Kildsig DO. Effect of nicotinamide and urea on the solubility of riboflavin in various solvents. J Pharm Sci. 1996;85(9):951-4. doi: 10.1021/ js960012b, PMID 8877885.

19. Reddy PDM, Nur SBR, Huei RO, Chin KC, Maksudur RK, et al. Preparation and characterization of photocatalyst for the conversion of carbon dioxide to methanol. Int J Chem Mol Nucl Mater Metall Eng. 2016;10(5):515. doi: 10.5281/zenodo.1124115.

20. Laxman M, Sharma MM. Reduction of Isophorone With Sodium Borohydride: Change in Regioselectivity with Hydrotropes. Synth Commun. 1990;20(1):111-7. doi: 10.1080/00397919008054621.
21. Jayakumar C, Devi VM, Reddy Prasad DM, Sridar R. Oil extraction from TrichosanthestricuspidataSeed using conventional Soxhlet apparatus. Asian J Chem. 2019;32(1):9-12. doi: 10.14233/ajchem.2020.21959.

22. Neumann MG, Schmitt CC, Prieto KR, Goi BE. The photophysical determination of the minimum hydrotrope concentration of aromatic hydrotropes. J Colloid Interface Sci. 2007;315(2):810-3. doi: 10.1016/j. jcis.2007.07.020, PMID 17681515.

23. DudukuKrishnaiah, Reddy Prasad AwangB, Rosalamsarbatly. Application of ultrasonic coupled with functional link neural network for estimation of carrageenan concentration. Int J Phys Sci. 2008;3(4):090-6. doi: 10.5897/ IJPS. 9000082.

24. Taki S, Badens E, Charbit G. Controlled release system formed by supercritical anti-solvent coprecipitation of a herbicide and a biodegradable polymer. The Journal of Supercritical Fluids. 2001;21(1):61-70. doi: 10.1016/ S0896-8446(01)00076-6.

25. Krishnaiah D, Reddy PDM, Sarbatly R, Bono A, Anisuzzaman SM, Krishnaiah KK. Solid-liquid mass transfer coefficients in an ultrasoundirradiated extraction of iota-carrageenan. Dev Sustain Chem Bioprocess Technol. 2013;10:249. doi: 10.1007/978-1-4614-6208-8_31.

26. Rubino JT, Yalkowsky SH. Cosolvency and deviations from log-linear solubilization. Pharm Res. 1987;4(3):231-6. doi: 10.1023/A:1016408211963, PMID 3509286.

27. Strickley RG. Solubilizing excipients in oral and injectable formulations. Pharm Res. 2004;21(2):201-30. doi: 10.1023/B:PHAM.0000016235.32639.23, PMID 15032302.

28. Ramesh N, Jayakumar C, Nagendra Gandhi N. Effective separation of petro products through hydrotropy. Chem Eng Technol. 2009;32(1):129-33. doi: 10.1002/ceat.200800328.

29. Prasad R, Krishnaiah D, Bono A, Pandiyan P, Yunus RBM, Lakshmi N. Estimation of carrageenan Concentration by using ultrasonic waves and Back propagation Neural Networks. J Appl Sci. 2010;10(21):2729-32. doi: 10.3923/ jas.2010.2729.2732.

30. Mohanasundaram R, Jayakumar C, Gandhi NN. Separation of styrene- ethyl benzene mixture through hydrotropy. Int J Appl Sci Eng. 2010;8:1-9. doi: 10.6703/IJASE.2010.8(1).1.

\section{SUMMARY}

In the present research work, increasing the liquid solubility of insoluble and sparingly soluble drugs is of major importance. Hydrotropy may be a distinctive development to reinforce the liquid solubility of poorly water-soluble drugs. The term hydrotropy has been wont to designate the rise in the solubility of assorted substances in water because of the presence of enormous amounts of additives. Sodium salicylate, sodium benzoate, and resorcinol are utilized to reinforce the liquid solubility of many poorly soluble drugs. Varied organic solvents like methyl alcohol, chloroform, alcohol, dimethylformamide, and benzene are utilized for the solubilization of poorly soluble drugs. Theophylline drug was accessories to numerous hydrotrope concentrations (0-3 mol/L) and also the non-inheritable sample for a solubility determination was analyzed in an exploitation UV spectrophotometer. It has been distinctively observed and noted that the solubility of theophylline increases with an increase in a hydrotrope concentration and also with a system temperature likely similar to the several organic compounds and drugs. The maximum enhancement factor, which is the ratio of the value within the presence and absence of a hydrotrope, has been determined for all sets of experimentations. To determine the hydrotropic aggregation behaviour of theophylline, thermodynamic parameters like Gibb's free energy, enthalpy, and entropy of theophylline were determined. Gibb's free energy decreases with a rise in system temperature. The aggregation of hydrotropes was found to be exothermic and favoured by a positive value of entropy. 


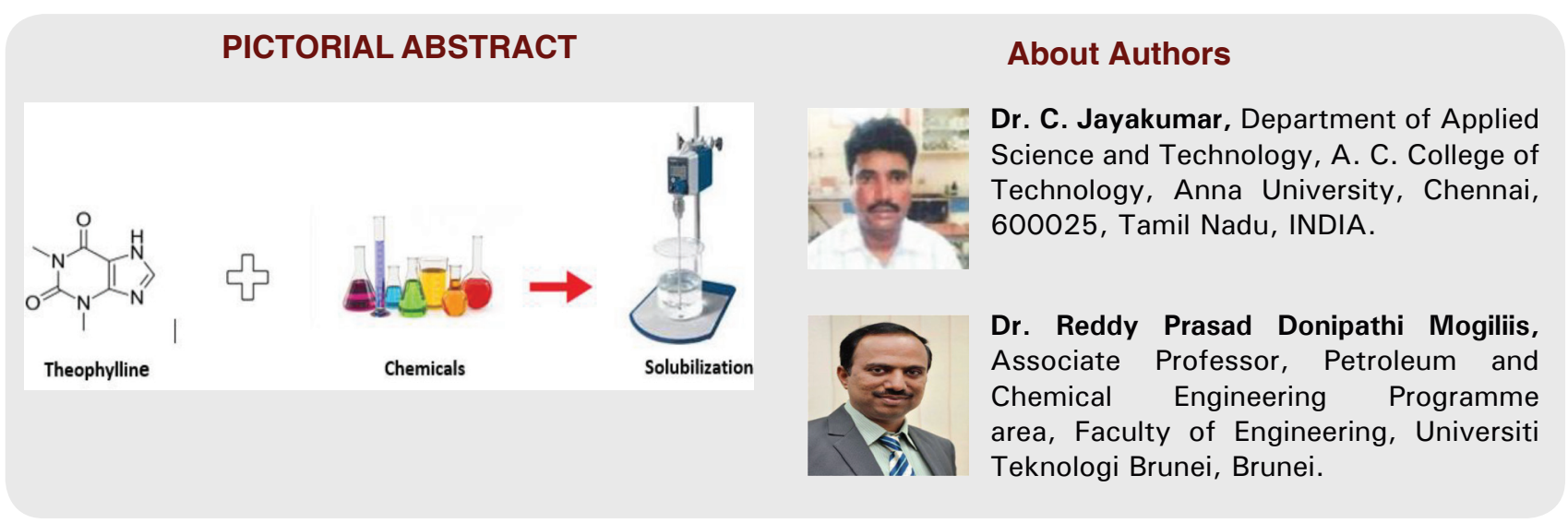

Cite this article: Jayakumar C, Reddy Prasad DM. Thermodynamic Study on Hydrotropic Aggregation Behavior of Theophylline. Indian J of Pharmaceutical Education and Research. 2021;55(3s):s693-s699. 